\title{
Impact of Carbon Dioxide on Cerebral Oxygenation and Vital Parameters in Stable Preterm and Term Infants Immediately after Birth
}

\author{
Christina Helene Wolfsberger ${ }^{a, b}$ Marlies Bruckner ${ }^{a, b} \quad$ Bernhard Schwaberger $^{a, b}$ \\ Lukas Peter Mileder $^{a, b} \quad$ Berndt Urlesberger ${ }^{a, b} \quad$ Gerhard Pichler $^{a}$, b \\ aDivision of Neonatology, Department of Pediatrics and Adolescent Medicine, Medical University of Graz, Graz, \\ Austria; ${ }^{b}$ Research Unit for Neonatal Micro- and Macrocirculation, Department of Paediatrics and Adolescent \\ Medicine, Medical University of Graz, Graz, Austria
}

\section{Keywords}

Preterm infants · Transition · Near-infrared spectroscopy ·

Regional cerebral oxygen saturation - Carbon dioxide

\begin{abstract}
Introduction: Carbon dioxide $\left(\mathrm{pCO}_{2}\right)$ induces changes in the tone of cerebral vessels. The aim of the present study was to evaluate the impact of $\mathrm{pCO}_{2}$ on cerebral regional tissue oxygen saturation $\left(\mathrm{crSO}_{2}\right)$, cerebral fractional tissue oxygen extraction (cFTOE), and cerebral tissue oxygen extraction (cTOE), measured with near-infrared spectroscopy (NIRS), in preterm and term infants 15 min after birth. Methods: Post hoc analyses of secondary outcome parameters of prospective observational studies were performed. Stable preterm and term infants with cerebral NIRS monitoring (INVOS 5100C) until minute 15 after birth and a blood gas analysis, performed between minutes 14-18 after birth, were included. Heart rate $(\mathrm{HR})$ and arterial oxygen saturation $\left(\mathrm{SpO}_{2}\right)$ were recorded. $\mathrm{pCO}_{2}$ was correlated with $\mathrm{CrSO}_{2}, \mathrm{cFTOE}$, cTOE, $\mathrm{SpO}_{2}, \mathrm{HR}$, and partial pressure of oxygen $\left(\mathrm{pO}_{2}\right) \cdot \boldsymbol{R} \boldsymbol{e}-$ sults: Eleven preterm infants with a median (IQR) gestational age of 34.8 (32.7-36.1) weeks were analyzed. Mean \pm SD $\mathrm{pCO}_{2}$ was $53.5 \pm 4.2 \mathrm{~mm} \mathrm{Hg}$. At minute 15 after birth, $\mathrm{CrSO}_{2}$
\end{abstract}

karger@karger.com www.karger.com/neo

Karger $\stackrel{\text { ' }}{5}$

GOPEN ACCESS
(C) 2021 The Author(s)

Published by S. Karger AG, Basel

This is an Open Access article licensed under the Creative Commons Attribution-NonCommercial-4.0 International License (CC BY-NC) (http://www.karger.com/Services/OpenAccessLicense), applicable to the online version of the article only. Usage and distribution for commercial purposes requires written permission. was 82.6 (74.3-91.3)\%, cFTOE $0.15 \pm 0.09$, cTOE $14.6 \pm 8.4 \%$, $\mathrm{SpO}_{2} 97.4 \pm 2.1 \%$, and HR 152 (136-167) bpm. $\mathrm{pCO}_{2}$ correlated negatively with $\mathrm{crSO}_{2}(p=0.012)$ and positively with cFTOE $(p=0.035)$ and cTOE $(p=0.037)$. Eighty-four term infants with a gestational age of 39.0 (38.5-38.9) weeks were analyzed. $\mathrm{pCO}_{2}$ was $53.5 \pm 6.3 \mathrm{~mm} \mathrm{Hg}$. At minute 15 after birth, $\mathrm{crSO}_{2}$ was $84.4(80.8-85.1) \%$, cFTOE $0.14 \pm 0.08$, cTOE $13.6 \pm 7.9 \%, \mathrm{SpO}_{2} 96.5 \pm 2.6 \%$, and HR 155 (153-163) bpm. $\mathrm{pCO}_{2}$ did only negatively correlate with $\mathrm{pO}_{2}(p=0.034)$ in term infants. Conclusion: In preterm infants, higher $\mathrm{pCO}_{2}$ was associated with lower $\mathrm{CrSO}_{2}$ and higher $\mathrm{CFTOE} / \mathrm{cTOE}$. In term infants, no associations were observed. The present findings suggest that the vasodilatative effect of $\mathrm{pCO}_{2}$ is less pronounced in preterm infants during immediate postnatal transition.

(c) 2021 The Author(s).

Published by S. Karger AG, Basel

\section{Introduction}

Carbon dioxide $\left(\mathrm{pCO}_{2}\right)$ is one of the most potent mediators of cerebral autoregulation inducing changes in cerebral vessels' tone and influencing cerebral blood flow (CBF) $[1,2]$. Cerebral autoregulation enables constant 
$\mathrm{CBF}$, independent of changes in cerebral perfusion pressure as long as the blood pressure range is within the autoregulatory plateau [3]. Above the autoregulatory plateau, CBF increases and below, CBF decreases in a pressure-passive manner [4]. An impaired autoregulation leads to linear changes of $\mathrm{CBF}$ depending on changes in blood pressure [5]. An increase in $\mathrm{pCO}_{2}$ attenuates $\mathrm{CBF}$ autoregulation. Higher $\mathrm{pCO}_{2}$ is associated with cerebral vasodilatation and an increase in $\mathrm{CBF}$, while a reduction in $\mathrm{pCO}_{2}$ leads to cerebral vasoconstriction and a decrease in $\mathrm{CBF}[6,7]$. Significant fluctuations in $\mathrm{pCO}_{2}$ have already been described to be associated with neurodevelopmental morbidities, whereby fluctuations and extreme high or low values within the first few days after birth are associated with a higher risk of cerebral impairment $[8$, 9].

Cerebral regional tissue oxygen saturation $\left(\mathrm{crSO}_{2}\right) \mathrm{can}$ be monitored by continuous noninvasive measurements of oxygenated $\left(\mathrm{HbO}_{2}\right)$ and deoxygenated hemoglobin $\mathrm{Hb})$ using near-infrared spectroscopy (NIRS) [10, 11]. Near-infrared light propagates through tissue, and certain wavelengths are differently absorbed by $\mathrm{HbO}_{2}$ and $\mathrm{Hb}$ [12]. Cerebral fractional tissue oxygen extraction (cFTOE) and cerebral tissue oxygen extraction (cTOE) can be calculated out of $\mathrm{crSO}_{2}$ and arterial oxygen saturation $\left(\mathrm{SpO}_{2}\right)$.

Monitoring of cerebral oxygenation with NIRS in the delivery room during the immediate fetal-to-neonatal transition period is well established $[13,14]$. Low cerebral oxygenation during immediate transition is associated with cerebral injury [15], whereby cerebral oxygenation can be improved by using NIRS monitoring and dedicated interventions [16]. However, knowledge of influencing parameters on cerebral oxygenation during immediate uncomplicated transition is still limited. Metabolic parameters like blood glucose [17] and circulatory parameters like ductus arteriosus and persistent foramen ovale have been demonstrated to influence cerebral oxygenation $[18,19]$. However, so far, there are no investigations on the potential influence of $\mathrm{pCO}_{2}$ on $\mathrm{CrSO}_{2}, \mathrm{cFTOE}$, and cTOE in stable infants during the immediate transition after birth - within the first 15 min after life.

The aim of the present study was therefore to evaluate the potential correlation between $\mathrm{pCO}_{2}$ and $\mathrm{crSO}_{2}$, cFTOE, and cTOE (measured with NIRS), with routine monitoring parameters $\left(\mathrm{SpO}_{2}\right.$, heart rate $[\mathrm{HR}]$, mean arterial blood pressure [MABP], and rectal body temperature), with partial pressure of oxygen $\left(\mathrm{pO}_{2}\right)$, and with blood glucose in preterm and term infants without medical support $15 \mathrm{~min}$ after birth. We hypothesized that higher $\mathrm{pCO}_{2}$ values would be associated with higher $\mathrm{CrSO}_{2}$ and lower cFTOE and cTOE values $15 \mathrm{~min}$ after birth due to increased CBF as a result of vasodilatation, with a weaker effect in preterm infants due to their more immature autoregulation.

\section{Materials and Methods}

Design

In the present study, a post hoc analysis of secondary outcome parameters of prospective observational studies, conducted at the Division of Neonatology, Department of Paediatrics and Adolescent Medicine, Medical University of Graz, Austria, between July 2009 and September 2018, was performed. The studies were approved by the Regional Committee on Biomedical Research Ethics (EC Nos. 19-291 ex 07/08, 23-403 ex 10/11, and 27-465 ex 14/15). Written parental informed consent was obtained before birth and inclusion in each study.

\section{Inclusion and Exclusion Criteria}

Preterm and term infants delivered by caesarean section, who received cerebral NIRS monitoring during the first $15 \mathrm{~min}$ after birth as participants of one of the prospective observational studies, were included. Furthermore, for inclusion into the present post hoc analysis, a heel-stick blood sample for blood gas and hemoglobin analysis was required. This had to be performed within 14-18 min after birth at the discretion of the respective attending neonatologist, to correlate the results with the NIRS and routine monitoring parameters at minute 15 after birth. Exclusion criteria were major congenital malformations and the need for supplemental oxygen and/or (non-)invasive respiratory support.

\section{Monitoring}

Antepartum medical histories were collected, and demographic data including gestational age, birth weight, sex, umbilical artery $\mathrm{pH}$, Apgar scores, $\mathrm{Hb}$ concentration, and fetal hemoglobin $(\mathrm{HbF})$ concentration were documented. Cord clamping was routinely delayed for $30 \mathrm{~s}$ after birth. Infants were dried and placed in the supine position under an overhead heater. The NIRS sensor was fixed on the left frontoparietal head using a modified CPAP cap or an elastic gauze bandage immediately after birth. NIRS measurements $\left(\mathrm{crSO}_{2}\right)$ were performed with the INVOS 5100C Cerebral/ Somatic Oximeter Monitor (Medtronic, Minneapolis, MN, USA) with a neonatal transducer. Pulse oximetry was applied on the infants' right hand or wrist. $\mathrm{SpO}_{2}$ and $\mathrm{HR}$ were measured with the IntelliVue MP30 monitor (Koninklijke Philips, The Netherlands). The monitoring was performed continuously during the first 15 min after birth. cFTOE and cTOE were calculated out of $\mathrm{SpO}_{2}$ and $\mathrm{crSO}_{2}$ by the following formulas: $\mathrm{cFTOE}=\left(\mathrm{SpO}_{2}-\mathrm{crSO}_{2}\right) / \mathrm{SpO}_{2}$ and $\mathrm{cTOE}=\mathrm{SpO}_{2}-\mathrm{crSO}_{2}[20]$.

For noninvasive blood pressure measurements (IntelliVue MP50 monitor; Koninklijke Philips, The Netherlands) at minute 15 after birth, the pneumatic cuff was placed on the infants' right upper arm. Rectal body temperature was routinely measured once in minute 15 after birth.

All variables were stored in the multichannel system alpha trace digital MM (BESTMedical Systems, Vienna, Austria) for subsequent analysis. For the present study, mean values of $\mathrm{crSO}_{2}, \mathrm{SpO}_{2}$, and $\mathrm{HR}$ 
Table 1. Demographic data and routine monitoring parameters

\begin{tabular}{|c|c|c|c|}
\hline Demographic data & $\begin{array}{l}\text { Preterm infants } \\
(n=11)\end{array}$ & $\begin{array}{l}\text { Term infants } \\
(n=84)\end{array}$ & $p$ value \\
\hline Gestational age, weeks & $34.8(32.7-36.1)$ & $39.0(38.5-38.9)$ & $<0.001^{*}$ \\
\hline Birth weight, $g$ & $2,101 \pm 370$ & $3,145 \pm 441$ & $<0.001^{*}$ \\
\hline Female sex & $7(64)$ & $35(42)$ & 0.171 \\
\hline Umbilical artery $\mathrm{pH}$ & $7.27(7.23-7.32)$ & $7.32(7.30-7.32)$ & $0.005^{*}$ \\
\hline Apgar 1 min & $9(9-9)$ & $9(9-9)$ & 0.549 \\
\hline Apgar 5 min & $10(10-10)$ & $10(10-10)$ & 0.194 \\
\hline Apgar $10 \mathrm{~min}$ & $10(10-10)$ & $10(10-10)$ & 0.716 \\
\hline \multicolumn{4}{|l|}{ NIRS parameters } \\
\hline $\mathrm{crSO}_{2}, \%$ & $82.6(74.3-91.3)$ & $84.4(80.8-85.1)$ & 0.398 \\
\hline cFTOE & $0.15 \pm 0.09$ & $0.14 \pm 0.08$ & 0.615 \\
\hline cTOE, \% & $14.6 \pm 8.4$ & $13.6 \pm 7.9$ & 0.693 \\
\hline \multicolumn{4}{|l|}{ Routine monitoring } \\
\hline $\mathrm{SpO}_{2}, \%$ & $97 \pm 2$ & $97 \pm 3$ & 0.201 \\
\hline $\mathrm{HR}, \mathrm{bpm}$ & $152(136-167)$ & $155(153-163)$ & 0.661 \\
\hline $\mathrm{MABP}, \mathrm{mm} \mathrm{Hg}$ & $46(40-50)$ & $45(45-50)$ & 0.276 \\
\hline Blood pressure systolic, mm Hg & $62(59-68)$ & $62(55-66)$ & 0.936 \\
\hline Blood pressure diastolic, $\mathrm{mm} \mathrm{Hg}$ & $34(31-39)$ & $36(32-44)$ & 0.365 \\
\hline Rectal body temperature, ${ }^{\circ} \mathrm{C}$ & $36.8 \pm 0.4$ & $37.0 \pm 0.3$ & $0.045^{*}$ \\
\hline \multicolumn{4}{|l|}{ Partial pressure of $\mathrm{pCO}_{2}$ and $\mathrm{pO}_{2}, \mathrm{~mm} \mathrm{Hg}$} \\
\hline $\mathrm{pCO}_{2}$ & $53.5 \pm 4.2$ & $53.5 \pm 6.3$ & 0.774 \\
\hline $\mathrm{pO}_{2}$ & $45.3 \pm 9.2$ & $41.0 \pm 5.4$ & 0.196 \\
\hline \multicolumn{4}{|l|}{ Hemoglobin } \\
\hline $\mathrm{Hb}, \mathrm{g} / \mathrm{dL}$ & $18.9 \pm 2.5$ & $18.9 \pm 1.7$ & 0.896 \\
\hline $\mathrm{HbF}, \%$ & $77.8 \pm 5.8$ & $72.2 \pm 5.7$ & $0.011^{*}$ \\
\hline \multicolumn{4}{|l|}{ Blood glucose and $\mathrm{pH}$} \\
\hline Glucose $\mathrm{mg} / \mathrm{dL}$ & $50.5(46.5-57.5)$ & $50.0(49.1-53.3)$ & 0.774 \\
\hline $\mathrm{pH}$ & $7.29 \pm 0.04$ & $7.29 \pm 0.04$ & 0.942 \\
\hline
\end{tabular}

Data are presented as mean $\pm \mathrm{SD}$, median (IQR), or $n(\%)$. NIRS, near-infrared spectroscopy; $\mathrm{crSO}_{2}$, cerebral regional tissue oxygen saturation; CFTOE, cerebral fractional tissue oxygen extraction; CTOE, cerebral tissue oxygen extraction; $\mathrm{SpO}_{2}$, arterial oxygen saturation; $\mathrm{HR}$, heart rate; $\mathrm{MABP}$, mean arterial blood pressure; $\mathrm{pCO}_{2}$, partial pressure of carbon dioxide; $\mathrm{pO}_{2}$, partial pressure of oxygen; $\mathrm{Hb}$, hemoglobin; $\mathrm{HbF}$, fetal hemoglobin. ${ }^{*} p$ value indicates significant difference between preterm and term infants.

obtained during a 60 -s period at minute 15 after birth were analyzed. Values of $\mathrm{SpO}_{2}$ and $\mathrm{HR}$ were stored every second, whereby the sampling rate for $\mathrm{CrSO}_{2}$ was $8 \mathrm{~s}$. As a quality criterion, values of $\mathrm{crSO}_{2}$ and $\mathrm{SpO}_{2}$ were eliminated when $\mathrm{crSO}_{2}$ was higher than $\mathrm{SpO}_{2}$.

\section{Blood Analysis}

$\mathrm{pCO}_{2}, \mathrm{pO}_{2}, \mathrm{Hb}, \mathrm{HbF}$, glucose values, and $\mathrm{pH}$ were obtained from capillary blood (ABL 800 Flex; Fa. Drott, Wiener Neustadt, Austria) according to the local standard operating procedures.

\section{Statistical Analysis}

Demographic, NIRS, and routine monitoring data are presented as $n(\%)$, mean and standard deviation, or median and interquartile range, as appropriate. Comparisons of categorical baseline characteristics $\left(\mathrm{pCO}_{2}\right.$, demographic and monitoring data, and results of blood analyses) between preterm and term infants were performed using the $\chi^{2}$ test and for continuous variables using the $t$ test or Mann-Whitney $U$ test, as appropriate. Correlation analy- ses between $\mathrm{pCO}_{2}$ and NIRS parameters $\left(\mathrm{crSO}_{2}, \mathrm{cFTOE}\right.$, and cTOE), clinical routine monitoring parameters $\left(\mathrm{SpO}_{2}, \mathrm{HR}, \mathrm{MABP}\right.$, and rectal temperature), $\mathrm{pO}_{2}$, and blood glucose were calculated separately for preterm and term infants using Pearson correlation for normally distributed data and the Spearman's rank correlation for not normally distributed data.

A $p$ value $<0.05$ was considered statistically significant. These values were considered in an explorative sense; therefore, no multiple testing corrections were performed. Statistical analyses were performed using SPSS Statistics 24 (IBM, Armonk, NY, USA).

\section{Results}

A total of 148 preterm and 511 term infants, who were included in the prospective observational studies, were eligible. Eleven preterm and 84 term infants were
12

Neonatology 2022;119:10-17 DOI: $10.1159 / 000519636$
Wolfsberger/Bruckner/Schwaberger/ Mileder/Urlesberger/Pichler 
Table 2. Correlations between $\mathrm{pCO}_{2}$ and NIRS parameters, routine monitoring parameters, $\mathrm{pO}_{2}$, and blood glucose in preterm and term infants

\begin{tabular}{|c|c|c|c|c|c|c|}
\hline & \multicolumn{3}{|c|}{ Preterm infants } & \multicolumn{3}{|c|}{ Term infants } \\
\hline & \multicolumn{3}{|c|}{$\mathrm{pCO}_{2}$} & \multicolumn{3}{|c|}{$\mathrm{pCO}_{2}$} \\
\hline & $n$ & $r$ & $p$ value & $n$ & $r$ & $p$ value \\
\hline \multicolumn{7}{|l|}{ NIRS parameters } \\
\hline $\mathrm{crSO}_{2}(\%)$ & 11 & -0.720 & $0.012^{*}$ & 84 & 0.028 & 0.801 \\
\hline cFTOE & 11 & 0.636 & $0.035^{*}$ & 84 & -0.008 & 0.946 \\
\hline cTOE (\%) & 11 & 0.632 & $0.037^{*}$ & 84 & 0.001 & 0.993 \\
\hline \multicolumn{7}{|l|}{ Routine monitoring } \\
\hline $\mathrm{SpO}_{2}(\%)$ & 11 & -0.389 & 0.237 & 84 & 0.113 & 0.307 \\
\hline $\mathrm{HR}(\mathrm{bpm})$ & 11 & 0.442 & 0.174 & 84 & -0.184 & 0.094 \\
\hline $\mathrm{MABP}(\mathrm{mm} \mathrm{Hg})$ & 11 & 0.484 & 0.131 & 84 & -0.044 & 0.697 \\
\hline Rectal body temperature $\left({ }^{\circ} \mathrm{C}\right)$ & 11 & 0.050 & 0.884 & 84 & -0.179 & 0.113 \\
\hline \multicolumn{7}{|l|}{ Partial pressure of oxygen } \\
\hline $\mathrm{pO}_{2}(\mathrm{~mm} \mathrm{Hg})$ & 11 & -0.321 & 0.335 & 82 & -0.235 & $0.034^{*}$ \\
\hline \multicolumn{7}{|l|}{ Blood glucose } \\
\hline Glucose (mg/dL) & 10 & 0.407 & 0.243 & 79 & -0.022 & 0.847 \\
\hline
\end{tabular}

NIRS, near-infrared spectroscopy; $\mathrm{CrSO}_{2}$, cerebral regional tissue oxygen saturation; $\mathrm{CFTOE}$, cerebral fractional tissue oxygen extraction; $\mathrm{cTOE}$, cerebral tissue oxygen extraction; $\mathrm{pCO}_{2}$, partial pressure of carbon dioxide; $\mathrm{pO}_{2}$, partial pressure of oxygen; $\mathrm{SpO}_{2}$, arterial oxygen saturation; $\mathrm{HR}$, heart rate; $\mathrm{MABP}$, mean arterial blood pressure. ${ }^{*} p$ value indicates significant difference.

finally included in the present observational study (shown in Fig. 1). Demographic data, NIRS and routine monitoring parameters, and results of the blood gas analysis of the included preterm and term infants are summarized in Table 1. Correlation analyses are presented in Table 2.

Capillary blood gas samples were taken at a median (interquartile range) of 16.5 (15.5-17.2) and 16.0 (15.916.5) minutes after birth in preterm and term infants, respectively. No differences were observed between preterm and term infants in NIRS parameters, $\mathrm{pCO}_{2}, \mathrm{pO}_{2}$ $\mathrm{Hb}$, blood glucose, and $\mathrm{pH}$. $\mathrm{HbF}$ was significantly higher in preterm compared to term infants (shown in Table 1). In routine monitoring, no statistically significant differences between preterm and term infants were observed except for rectal body temperature.

In preterm infants, $\mathrm{pCO}_{2}$ correlated significantly negatively with $\mathrm{CrSO}_{2}$ and positively with cFTOE and cTOE. Furthermore, in other parameters, no correlation with $\mathrm{pCO}_{2}$ was observed (shown in Fig. 2a-d; Table 2).

In term infants, $\mathrm{pCO}_{2}$ did not correlate with $\mathrm{crSO}_{2}$, cFTOE, cTOE, $\mathrm{SpO}_{2}, \mathrm{HR}, \mathrm{MABP}$, rectal temperature, or blood glucose. However, $\mathrm{pCO}_{2}$ correlated significantly negatively with $\mathrm{pO}_{2}$, nevertheless with only a weak correlation (shown in Fig. 2e-h; Table 2).

$\mathrm{pCO}_{2}$ and Cerebral Oxygenation

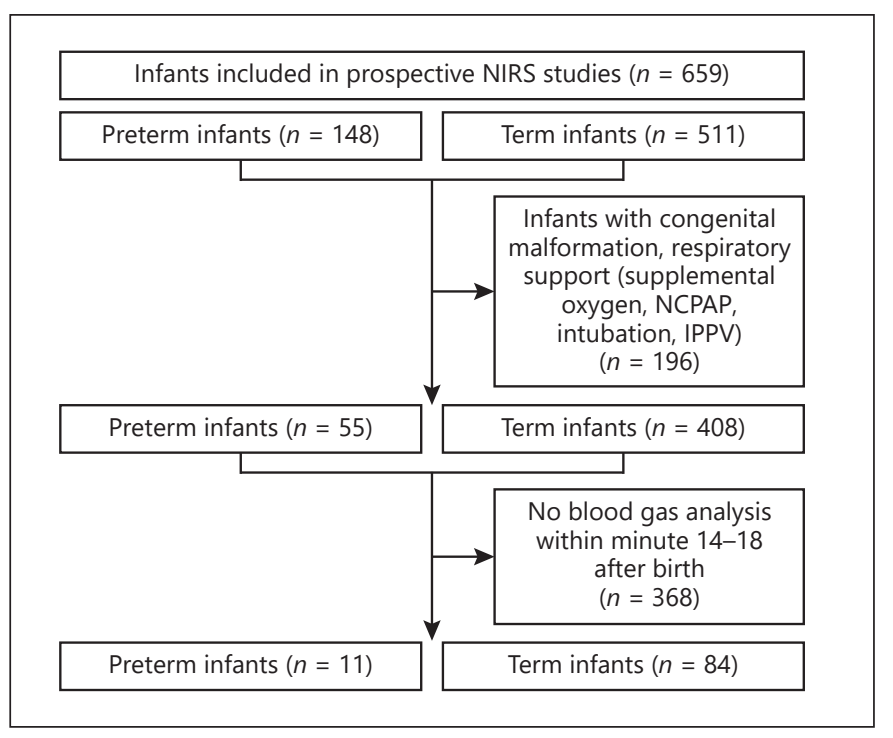

Fig. 1. Study flowchart showing the number of included and excluded preterm and term infants. NIRS, near-infrared spectroscopy.

\section{Discussion}

To our knowledge, this study is the first that analyzed potential correlations between $\mathrm{pCO}_{2}$ and cerebral oxygenation during the immediate fetal-to-neonatal transi- 


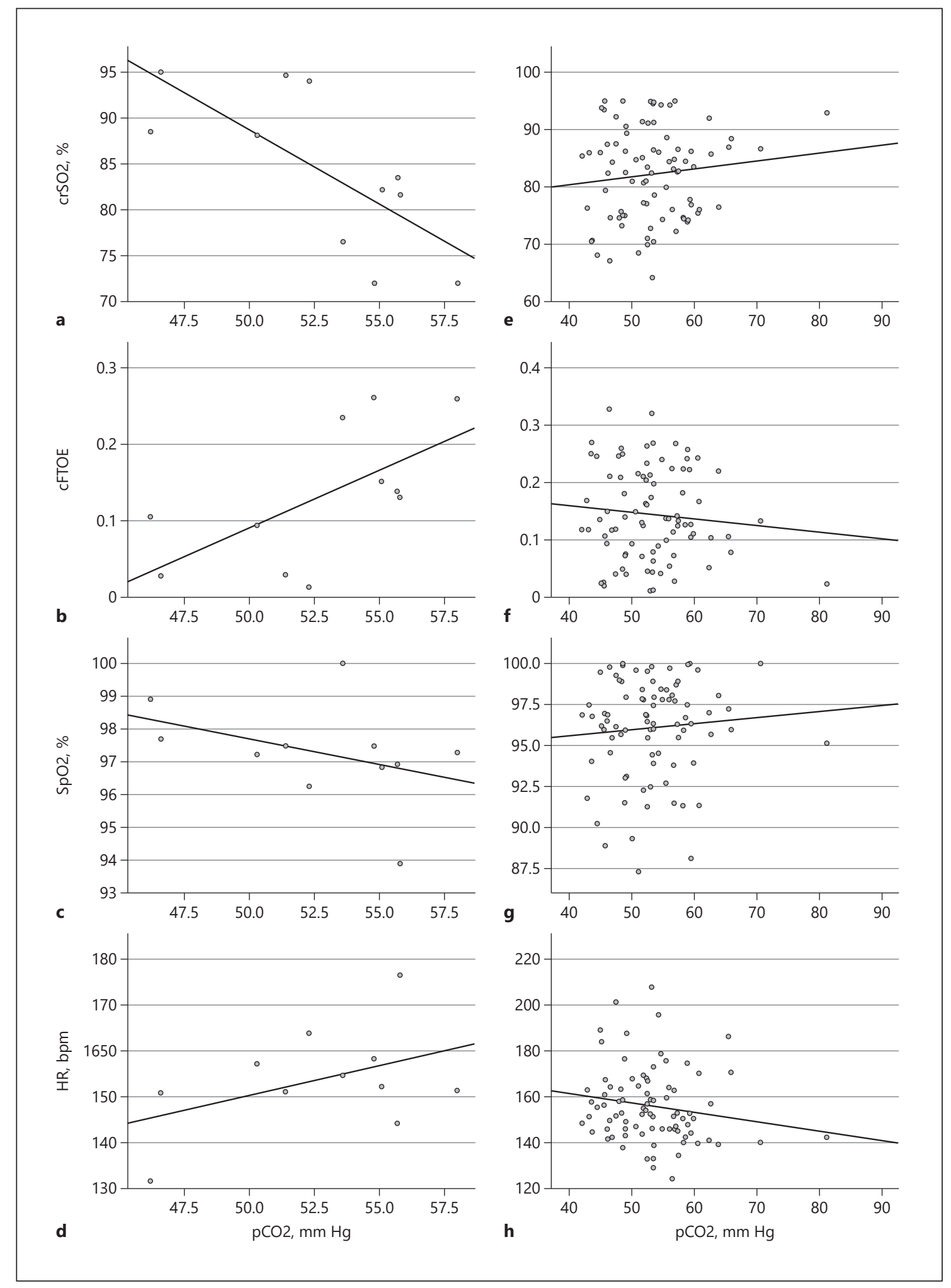

Fig. 2. Correlations of blood gas $\mathrm{pCO}_{2}$ and NIRS monitoring parameters ( $\mathrm{crSO}_{2}$ and cFTOE), routine parameters $\left(\mathrm{SpO}_{2}\right.$ and $\left.\mathrm{HR}\right)$, and gestational age in 11 preterm infants $(\mathbf{a}-\mathbf{d})$ and 84 term infants $(\mathbf{e}-\mathbf{h}) \cdot \mathrm{pCO}_{2}$, partial pressure of carbon dioxide; NIRS, near-infrared spectroscopy; $\mathrm{CrSO}_{2}$, cerebral regional tissue oxygen saturation; $\mathrm{cFTOE}$, cerebral fractional tissue oxygen extraction; $\mathrm{SpO}_{2}$, arterial oxygen saturation; $\mathrm{HR}$, heart rate. 
tion period in stable preterm and term infants. We showed that in preterm infants, $\mathrm{pCO}_{2}$ values correlated negatively with $\mathrm{CrSO}_{2}$ and positively with cFTOE and cTOE, whereas no such correlation was observed in term infants. Furthermore, in preterm infants, a trend to positive correlation of $\mathrm{pCO}_{2}$ with $\mathrm{HR}$ and MABP was observed. In term infants, there was no correlation between $\mathrm{pCO}_{2}$ and routine monitoring parameters.

Previous studies reported $\mathrm{pCO}_{2}$ values of $49-76 \mathrm{~mm}$ $\mathrm{Hg}$ at birth, with a decrease to $46-57 \mathrm{~mm} \mathrm{Hg}$ within the first 10 min after birth [21]. In our study, $\mathrm{pCO}_{2}$ values at 15 min after birth were within these ranges.

Correlations between $\mathrm{pCO}_{2}$ and cerebral oxygenation were more pronounced in preterm infants compared to term infants. However, the direction of the correlation in preterm infants was not as we expected, as contrary to our hypothesis, higher $\mathrm{pCO}_{2}$ values were associated with lower $\mathrm{CrSO}_{2}$ and higher cFTOE and cTOE values in preterm and term infants $15 \mathrm{~min}$ after birth. There are several hypotheses to explain these findings.

First, in the present study, preterm infants with higher $\mathrm{pCO}_{2}$ values showed a trend to lower $\mathrm{SpO}_{2}$ and $\mathrm{pO}_{2}$ values in minute 15 after birth. $\mathrm{SpO}_{2}$ and $\mathrm{pO}_{2}$ influence $\mathrm{CrSO}_{2}, \mathrm{cFTOE}$, and cTOE because oxygen delivery to the brain depends on $\mathrm{SpO}_{2}$ and $\mathrm{pO}_{2}$. Thus, lower $\mathrm{SpO}_{2}$ and $\mathrm{pO}_{2}$ values are associated with lower $\mathrm{crSO}_{2}$ and higher cFTOE and cTOE values. The association of lower $\mathrm{pO}_{2}$ with higher $\mathrm{PCO}_{2}$ might be explained by a prolonged pulmonary transition due to reduced aeration of the lungs even in clinically stable infants showing lower $\mathrm{SpO}_{2}$ values, though within normal ranges.

Second, immediately after birth, both $\mathrm{pCO}_{2}$ and $\mathrm{pO}_{2}$ are potent mediators for changes in cerebral vascular resistance. The strong vasodilatory influence of high $\mathrm{pCO}_{2}$ values is a well-known phenomenon. In spontaneously breathing preterm infants 2 and $3 \mathrm{~h}$ after birth, the $\mathrm{pCO}_{2}-$ CBF reactivity has already been demonstrated by Pryds et al. [22], whereby CBF is well regulated within normal ranges of $\mathrm{pCO}_{2}$ values. A similar effect of $\mathrm{pCO}_{2}$ on $\mathrm{CBF}$ was observed in preterm infants in need for mechanical respiratory support within the first 3 days after birth [7]. Changes of CBF are described to be between $10 \%$ and $30 \%$ per $\mathrm{kPa}$ of $\mathrm{pCO}_{2}$ in very preterm infants after immediate transition [23]. However, besides $\mathrm{pCO}_{2}, \mathrm{pO}_{2}$ is one of the most potent mediators inducing changes in the tone of the cerebral vessel and influences cerebral autoregulation and CBF. Below a $\mathrm{pO}_{2}$ threshold of approximately $50 \mathrm{~mm} \mathrm{Hg}$, an increase in $\mathrm{pO}_{2}$ has a strong vasoconstrictive effect on cerebral vessels [24]. $\mathrm{pO}_{2}$ levels usually increase from $15-20 \mathrm{~mm} \mathrm{Hg}$ to $46-57 \mathrm{~mm} \mathrm{Hg}$ within the first $10 \mathrm{~min}$ after birth [25]. The vasoconstrictive effect of the $\mathrm{pO}_{2}$ increases during immediate transition, up to minute 15 after birth, potentially may have outweighed the vasodilatative effect of higher $\mathrm{pCO}_{2}$ values [6]. A decrease in $\mathrm{pCO}_{2}$ values is further associated with a decrease in CBV in preterm and term infants within the first minutes after birth [24]. In summary, the present findings suggest that in preterm infants, the vasodilatative effect due to hypercarbia does not outweigh the vasoconstrictive effects of the increasing $\mathrm{pO}_{2}$ values after birth.

In addition, in both preterm and term infants, higher $\mathrm{pCO}_{2}$ levels were associated with lower $\mathrm{pO}_{2}$ levels reaching significant negative correlation only in term infants. These associations suggest lower $\mathrm{crSO}_{2}$ levels with higher $\mathrm{pCO}_{2}$ due to the lower $\mathrm{pO}_{2}$ as observed in preterm infants. In term infants, however, higher $\mathrm{pCO}_{2}$ associated with lower $\mathrm{pO}_{2}$ was not associated with $\mathrm{crSO}_{2}$ suggesting that the vasodilatative effect of $\mathrm{pCO}_{2}$ increased $\mathrm{CBF}$ to maintain oxygen delivery to the brain.

Third, in the present study, preterm infants had higher HbF levels compared to term infants. Higher $\mathrm{HbF}$ concentrations lead to a left shift of the oxygen dissociation curve (ODC), causing an increased affinity for oxygen $\left(\mathrm{O}_{2}\right)$ [26] that might also explain the different findings in the 2 groups [27]. At birth, there is a predominance of $\mathrm{HbF}$, with a higher total amount in preterm infants compared to term infants. However, $\mathrm{HbF}$ is associated with reduced unloading of oxygen to tissue [28]. In the present study, the higher $\mathrm{HbF}$ in preterm infants results in ODC shift to the left causing a higher affinity of hemoglobin to oxygen, which may have partially antagonized the right shift of the ODC because of the higher $\mathrm{pCO}_{2}$. This may especially explain the increase of cFTOE and cTOE with increasing $\mathrm{pCO}_{2}$ values. Besides $\mathrm{HbF}$, the metabolic parameter blood glucose has already been described to correlate negatively with $\mathrm{crSO}_{2}$ [18]. In the present study, however, there was neither a difference in blood glucose levels between preterm and term infants nor a correlation between $\mathrm{pCO}_{2}$ and blood glucose that might have confounded the present findings.

Fourth, cerebral oxygenation is dependent on oxygen delivery to the brain which is influenced by cardiac output and blood flow in the large arteries. The cardiac output and blood flow in large arteries is influenced by stroke volume, HR, and shunts. HR showed a nonsignificant positive correlation with $\mathrm{pCO}_{2}$ in preterm infants that would suggest a higher cardiac output. However, since no echocardiography was performed, without information on stroke volume/myocardial function and 
especially on intra- and extracardial shunts, we cannot rule out cardiac output clearly. During the immediate postnatal transition period, the closure of the ductus arteriosus and foramen ovale leads to changes in the direction of the blood flow. In term infants, the closure of the ductus arteriosus starts immediately after birth, but it is completely closed in most term infants within $48-72 \mathrm{~h}$ after birth [29]. The influence of an open ductus arteriosus and foramen ovale on cerebral oxygenation plays an important role during postnatal transition [18]. Baik et al. [19] observed that the sum of ductus arteriosus and foramen ovale diameter correlated negatively with cerebral oxygen saturation due to higher left-to-right shunt volume in term infants. Furthermore, higher shunt volumes due to the ductus arteriosus and foramen ovale lead to more pronounced left-to-right steal phenomena. A comparable finding has been described by Fuchs et al. [30] in very-low-birth-weight infants, reporting that oxygen delivery to the brain depends on cardiac output. Lemmers et al. [31] described a reduction of $\mathrm{crSO}_{2}$ in preterm infants born before 32 weeks of gestation in association with a hemodynamically significant ductus arteriosus. The ductus arteriosus in preterm infants is thin walled and less muscular compared to those in term born infants, rendering a complete closure immediately after birth less likely [29]. Ductus arteriosus closure is less pronounced in preterm infants compared to term infants during immediate transition especially in case of hypercarbia due to its vasodilatative effect on the ductus arteriosus [32]. This hypothesis is further supported by the fact that the difference between systolic and diastolic blood pressure was more pronounced in preterm infants compared to the term infants in the present study. Therefore, in preterm infants, higher $\mathrm{pCO}_{2}$ values may be associated with a higher steal phenomenon compared to term, causing a decrease in $\mathrm{CBF}$ and oxygen delivery to the brain, ultimately leading to lower $\mathrm{CrSO}_{2}$ and higher cFTOE and cTOE.

\section{Limitations}

There were limitations in the present study. First, analyzed preterm and term infants showed $\mathrm{pCO}_{2}$ values within acceptable ranges for the immediate transition period. $\mathrm{pCO}_{2}$ values outside normal ranges, which are associated with an impaired autoregulation and changes in $\mathrm{CBF}$, might influence cerebral oxygenation, cFTOE, and cTOE more than it was observed in this present study. Second, no measures of CBF and cerebral blood volume were performed, as this study analyzed secondary outcome parameters of observational studies. Direct mea- sures of CBF might have allowed us to understand autoregulation better. Third, we can only assume a possible left-to-right shunt via the ductus arteriosus and foramen ovale especially in preterm infants, as no echocardiography was performed. Fourth, the number of analyzed preterm infants in this present study is quite low and included mainly moderate to late preterm infants, due to the inclusion criterion of no need for respiratory or medical support and the short time period between 14 and $18 \mathrm{~min}$ after birth for performing blood gas analysis.

To conclude, we found a significant negative correlation between $\mathrm{pCO}_{2}$ and $\mathrm{crSO}_{2}$ and a significant positive correlation between $\mathrm{pCO}_{2}$ and $\mathrm{cFTOE}$ and cTOE after immediate postnatal transition in preterm infants. There were no associations observed in term infants at all, except for $\mathrm{pCO}_{2}$ and $\mathrm{pO}_{2}$. The present findings suggest that the vasodilatative effect of high $\mathrm{pCO}_{2}$ levels that would normally result in an increase of cerebral perfusion and oxygen delivery and an increase of $\mathrm{crSO}_{2}$ levels is less pronounced in preterm infants during immediate transition. This vasodilatative effect of $\mathrm{pCO}_{2}$ is even outweighed by other influencing parameters causing a decrease in $\mathrm{crSO}_{2}$. This might be even more important in compromised extremely preterm infants, especially if $\mathrm{pCO}_{2}$ values are above or below normal ranges.

\section{Acknowledgments}

We thank the parents for their trust, so we were allowed to investigate their infants. We also thank all the staff members, especially Evelyn Ziehenberger, for contributing to this study.

\section{Statement of Ethics}

The studies analyzed in this post hoc analysis were approved by the Institutional Ethical Review Board of the Medical University of Graz, EC Nos. 19-291 ex 07/08, 23-403 ex 10/11, and 27-465 ex $14 / 15$. Written parental informed consent was obtained before birth and inclusion in each study.

\section{Conflict of Interest Statement}

The authors have no conflicts of interest to declare.

\section{Funding Sources}

No funding was received.
16

Neonatology 2022;119:10-17 DOI: $10.1159 / 000519636$
Wolfsberger/Bruckner/Schwaberger/ Mileder/Urlesberger/Pichler 


\section{Author Contributions}

C.W. and G.P. conceived the research idea and finalized the methods. C.W. and G.P. analyzed the data, and C.W. wrote the first draft. C.W., M.B., B.S., L.M., B.U., and G.P. contributed to data collection, interpretation of the results, drafting, and finalizing the manuscript.

\section{Data Availability Statement}

The data presented in this study are available on request from the corresponding author.

\section{References}

1 Levene MI, Shortland D, Gibson N, Evans DH. Carbon dioxide reactivity of the cerebral circulation in extremely premature infants: effects of postnatal age and indomethacin. Pediatr Res. 1988 Aug;24(2):175-9.

2 Greisen G. Autoregulation of cerebral blood flow in newborn babies. Early Hum Dev. 2005 May;81(5):423-8.

3 Harper AM. Autoregulation of cerebral blood flow: influence of the arterial blood pressure on the blood flow through the cerebral cortex. J Neurol Neurosurg Psychiatry. 1966 Oct; 29(5):398-403.

4 van de Bor M, Walther FJ. Cerebral blood flow velocity regulation in preterm infants. Biol Neonate. 1991;59(6):329-35.

5 Lou HC, Lassen NA, Friis-Hansen B. Impaired autoregulation of cerebral blood flow in the distressed newborn infant. J Pediatr. 1979 Jan;94(1):118-21.

6 Noori S, Anderson M, Soleymani S, Seri I. Effect of carbon dioxide on cerebral blood flow velocity in preterm infants during postnatal transition. Acta Paediatr. 2014 Aug;103(8): e334-9.

7 Pryds O, Greisen G. Effect of $\mathrm{PaCO} 2$ and haemoglobin concentration on day to day variation of CBF in preterm neonates. Acta Paediatr Scand Suppl. 1989;360:33-6.

8 Resch B, Neubauer K, Hofer N, Resch E, Maurer U, Haas J, et al. Episodes of hypocarbia and early-onset sepsis are risk factors for cystic periventricular leukomalacia in the preterm infant. Early Hum Dev. 2012 Jan;88(1):27-31.

9 Van de Bor M, Van Bel F, Lineman R, Ruys $\mathrm{JH}$. Perinatal factors and periventricular-intraventricular hemorrhage in preterm infants. Am J Dis Child. 1986 Nov; 140(11): 1125-30.

10 Jobsis F. Noninvasive, infrared monitoring of cerebral and myocardial oxygen sufficiency and circulatory parameters. Science. 1977 Dec;198(4323):1264-7.

11 Urlesberger B, Pichler G, Gradnitzer E, Reiterer F, Zobel G, Müller W. Changes in cerebral blood volume and cerebral oxygenation during periodic breathing in term infants. Neuropediatrics. 2000 Apr;31(2):75-81.

12 Wolf M, Greisen G. Advances in near-infrared spectroscopy to study the brain of the preterm and term neonate. Clin Perinatol. 2009 Dec;36(4):807.
13 Urlesberger B, Grossauer K, Pocivalnik M, Avian A, Müller W, Pichler G. Regional oxygen saturation of the brain and peripheral tissue during birth transition of term infants. J Pediatr. 2010 Nov;157(5):740-4.

14 Pichler G, Binder C, Avian A, Beckenbach E, Schmölzer GM, Urlesberger B. Reference ranges for regional cerebral tissue oxygen saturation and fractional oxygen extraction in neonates during immediate transition after birth. J Pediatr. 2013 Dec;163(6):1558-63.

15 Baik N, Urlesberger B, Schwaberger B, Schmölzer GM, Avian A, Pichler G. Cerebral haemorrhage in preterm neonates: does cerebral regional oxygen saturation during immediate transition matter? Arch Dis Child Fetal Neonatal Ed. 2015 Sep;100(5):F422-7.

16 Pichler G, Urlesberger B, Baik N, Schwaberger B, Binder-Heschl C, Avian A, et al. Cerebral oxygen saturation to guide oxygen delivery in preterm neonates for the immediate transition after birth: a 2-center randomized controlled pilot feasibility trial. J Pediatr. 2016 Mar; 170:73-4.

17 Matterberger C, Baik-Schneditz N, Schwaberger B, Schmölzer GM, Mileder L, PichlerStachl E, et al. Blood glucose and cerebral tissue oxygenation immediately after birth-an observational study. J Pediatr. 2018 Sep;200: 19-23.

18 Urlesberger B, Brandner A, Pocivalnik M, Koestenberger M, Morris N, Pichler G. A leftto-right shunt via the ductus arteriosus is associated with increased regional cerebral oxygen saturation during neonatal transition. Neonatology. 2013;103(4):259-63.

19 Baik N, Urlesberger B, Schwaberger B, Schmölzer GM, Köstenberger M, Avian A, et al. Foramen ovale (FO): the underestimated sibling of ductus arteriosus (DA): relevance during neonatal transition. Early Hum Dev. 2016 Dec;103:137-40.

20 Naulaers G, Meyns B, Miserez M, Leunens V, Van Huffel S, Casaer P, et al. Use of tissue oxygenation index and fractional tissue oxygen extraction as non-invasive parameters for cerebral oxygenation. A validation study in piglets. Neonatology. 2007;92(2):120-6.
21 Wyatt JS, Edwards AD, Cope M, Delpy DT, McCormick DC, Potter A, et al. Response of cerebral blood volume to changes in arterial carbon dioxide tension in preterm and term infants. Pediatr Res. 1991 Jun;29(6):553-7.

22 Pryds O, Andersen GE, Friis-Hansen B. Cerebral blood flow reactivity in spontaneously breathing, preterm infants shortly after birth. Acta Paediatr Scand. 1990 Apr;79(4):391-6.

23 Pryds O. Control of cerebral circulation in the high-risk neonate. Ann Neurol. 1991 Sep; 30(3):321-9.

24 Schwaberger B, Pichler G, Binder-Heschl C, Baik N, Avian A, Urlesberger B. Transitional changes in cerebral blood volume at birth. Neonatology. 2015;108(4):253-8.

25 Hand I, Krauss A, Auld P, Scarpelli E. Pulmonary physiology of the newborn infant. In: Scarpelli EM, editor. Pulmonary physiology of the Fetus. Philadelphia: Lea \& Febiger; 1992. p. 421-45.

26 Pritisanac E, Urlesberger B, Schwaberger B, Pichler G. Accuracy of pulse oximetry in the presence of fetal hemoglobin: a systematic review. Children. 2021 Apr;8(5):361.

27 Oski FA, Delivoria-Papadopoulos M. The shift to the left. Pediatrics. 1971 Dec;48(6): 853-6.

28 Stutchfield CJ, Jain A, Odd D, Williams C, Markham R. Foetal haemoglobin, blood transfusion, and retinopathy of prematurity in very preterm infants: a pilot prospective cohort study. Eye. 2017 Oct;31(10):1451-5.

29 Deshpande P, Baczynski M, McNamara PJ, Jain A. Patent ductus arteriosus: the physiology of transition. Semin Fetal Neonatal Med. 2018 Aug;23(4):225-31.

30 Fuchs H, Lindner W, Buschko A, Almazam M, Hummler HD, Schmid MB. Brain oxygenation monitoring during neonatal resuscitation of very low birth weight infants. J Perinatol. 2012 May;32(5):356-62.

31 Lemmers PM, Toet MC, van Bel F. Impact of patent ductus arteriosus and subsequent therapy with indomethacin on cerebral oxygenation in preterm infants. Pediatrics. 2008 Jan; 121(1):142-7.

32 Born GV, Dawes GS, Mott JC, Rennick BR The constriction of the ductus arteriosus caused by oxygen and by asphyxia in newborn lambs. J Physiol. 1956 May;132(2):304-42. 